\title{
Seroepidemiology of Toxocariasis in 2-12-year-old Children Refered to Health Centers in Kermanshah during 2018
}

\author{
Sirvan Mansouri' ${ }^{1}$, Mohammad Fallah², Amir Hossein Maghsood ${ }^{3}$, Mohammad Matini ${ }^{3}$,* \\ ${ }^{1}$ MSc in Parasitology, Hamadan University of Medical Sciences, Hamadan, Iran \\ 2 Professor, Department of Medical Parasitology and Mycology, School of Medicine, Hamadan University of Medical \\ Sciences, Hamadan, Iran \\ 3 Associate Professor, Department of Medical Parasitology and Mycology, School of Medicine, Hamadan University of \\ Medical Sciences, Hamadan, Iran \\ * Corresponding Author: Mohammad Matini, Department of Medical Parasitology and Mycology, School of Medicine, \\ Hamadan University of Medical Sciences, Hamadan, Iran.Email: matini@umsha.ac.ir
}

Received: 20.05 .2019 Accepted: 19.08 .2019

\section{How to Cite this Article:} Mansouri S, Fallah M, Maghsood AH, Matini M. Seroepidemiology of Toxocariasis in 2-12year-old Children Refered to Health Centers in Kermanshah during 2018. Avicenna J Clin Med. 2019; 26(2): 99-104. DOI: 10.21859/ajcm.26.2.99

\section{Abstract}

Background and Objective: Toxocariasis is a common infection between humans and animals, which can be considered as a health issue in vulnerable populations due to its indigenous nature to the country and the region. Therefore, the purpose of this study was to estimate the risk of contamination with Toxocara canis infection and exposure to its parasite in children.

Materials and Methods: This descriptive cross-sectional study was performed on 621 children aged 2 to12 years referred to health centers in Kermanshah, Iran. After sampling and recording the demographic characteristics, the samples were tested for anti-T. canis antibody (IgG) by enzyme-linked immunosorbent assay method. Data analysis was done using SPSS software and Fisher's exact test.

Results: Out of 621 tested serum samples, 8 samples (1.3\%) were positive for anti-Toxocara IgG antibodies. Of these, 5 and 3 samples were from male and female patients all living in urban areas. It is noteworthy that none of these individuals had a history of earth-eating, as well as touching or playing with the dog. However, a dog was kept at one of the child's home.

Conclusion: The results of the study showed a relatively low prevalence of toxocariasis infection in children, although the findings confirmed the establishment of the parasite transmission cycle in the region. Therefore, considering the importance of hygiene issues, it is necessary to develop and implement strategies for controlling and preventing the infection in the definitive hosts of the parasite in order to reduce the incidence of human infections.

Keywords: Seroepidemiology, Toxocara canis, Toxocariasis 
do): $10.21859 /$ ajcm.26.2.99

\title{
سروإيدميولوزى تو كسو كاريازيس در كودكان Y Y Y سال مراجعه كننده به مراكز

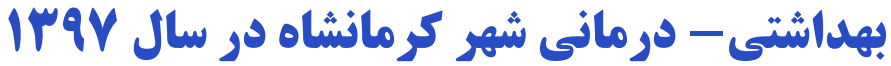

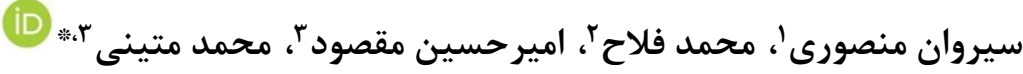 \\ ' كارشناسى ارشد انكل شناسى، دانشكاه علوم يزشكى همدان، همدان، ايران

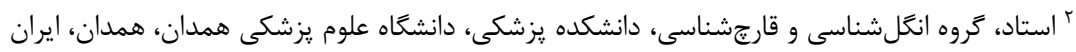

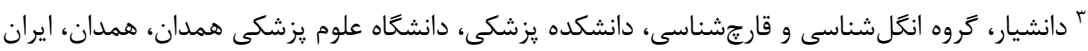
** نويسنده مسئول: محمد متينى، گروه انتلشناسى و قارجشناسى، دانشكده يزشكى، دانشخاه علوم يزشكى همدان، همدان، ايران. ايميل: matini@umsha.ac.ir

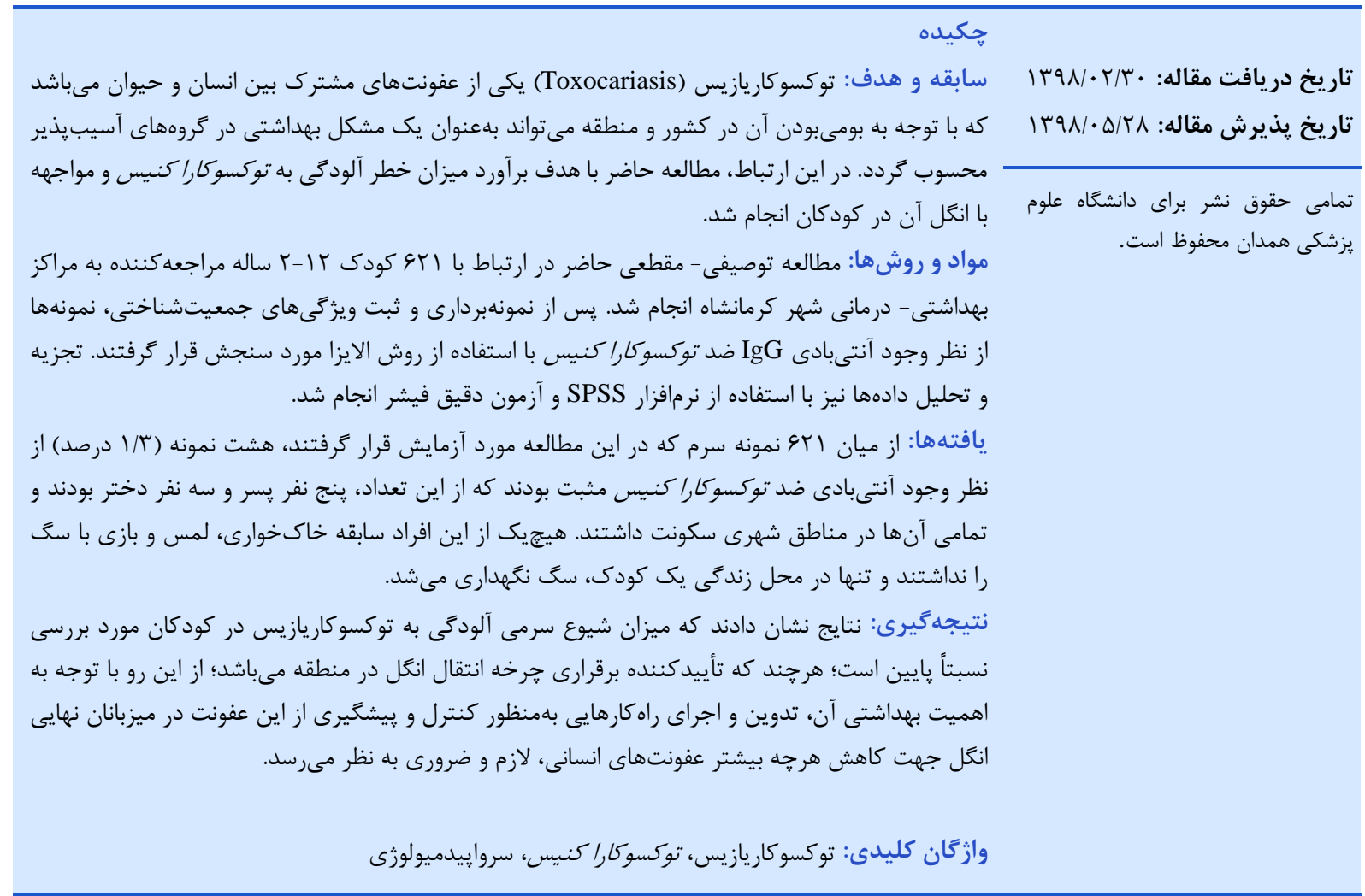

يراكندهشن در محيط باعث آلودگى محيط مىشوند. تخمها

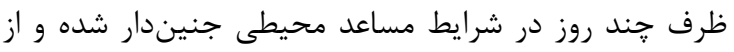

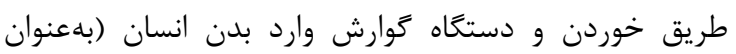

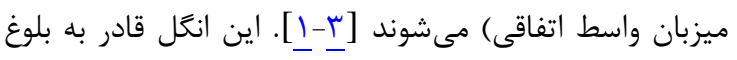

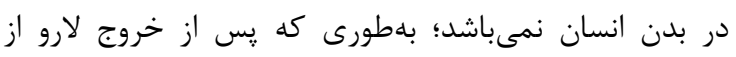

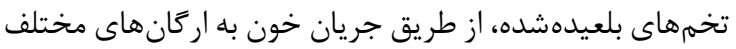

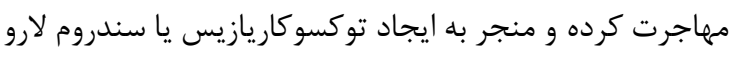

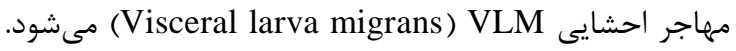

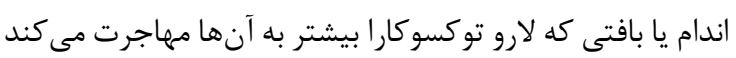

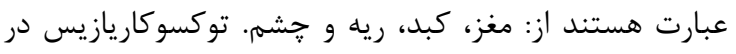

توكسو كاريازيس يكى از عفونتهاى مشترك انسان و حيوان

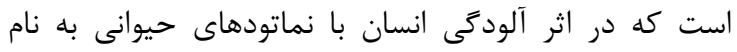

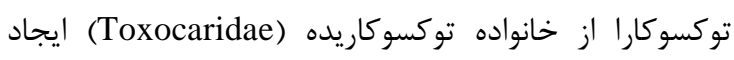

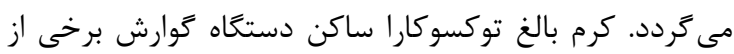

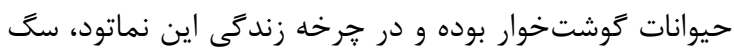
و كربه بهترتيب ميزبان نهايى توكسوكارا كنيس و توكسوكارا

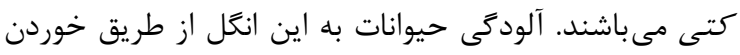

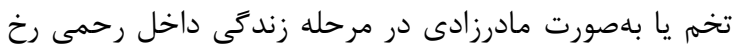

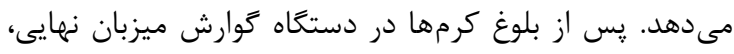

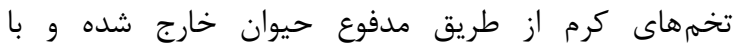


عفونت در انسان مورد استفاده قرار گيرند.

\section{مواد و روشها}

مطالعه توصيفى- مقطعى حاضر يس از تصويب در كميته

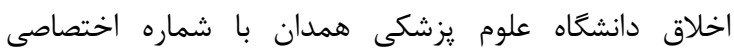

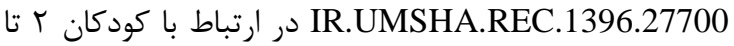
Ir سال مراجعه كننده به مراكز بهداشتى - درمانى شهر كرمانشاه در سال Vqr ا انجام شد.

در مطالعه حاضر شش مركز بهداشتى - درمانى بهصورت

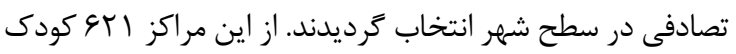

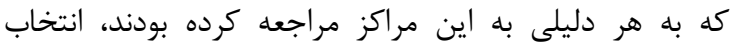

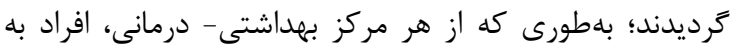

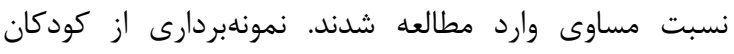
بلهصورت تصادفى و يس از كسب رضايت آحاهانه از والدين آنهانها

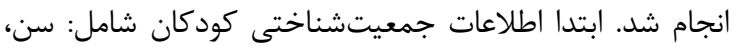
جنس، سابقه خاكخوارى، تماس با سگ و غيره جمعآورى شد آند

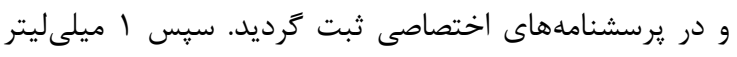

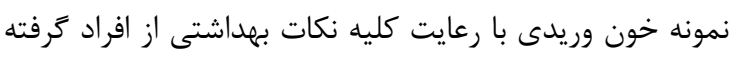

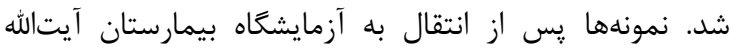

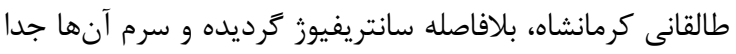

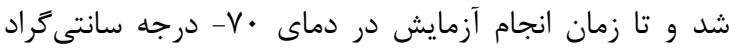
نكهدارى گرديد.

بلهنظور جستجوى آنتىبادى ضد توكسوكارا كنيس از

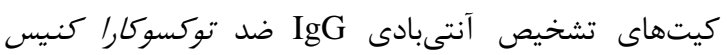
(ساخت شركت IBL آلمان) استفاده گرديد. ييش از از انجام آزمايش و آغاز كار، سرمهاى فريزشده، محلولها واخدا و سرمهاى كنترل در دماى اتاق قرار داده شدند تا براى آغاز فرايند كار آماده

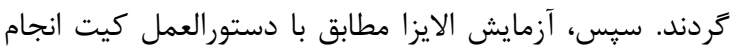

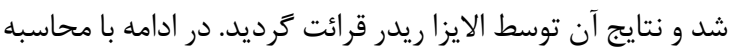

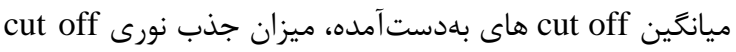

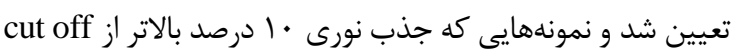

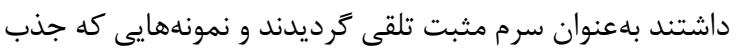

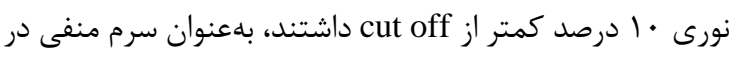

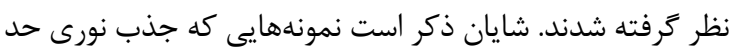

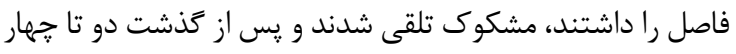

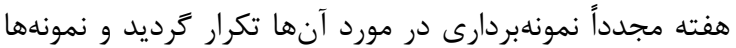

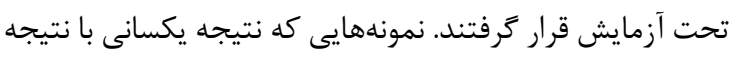

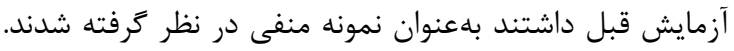

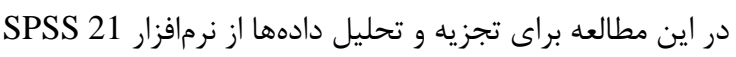
و آزمون دقيق فيشر استفاده گرديد.

يافته ها

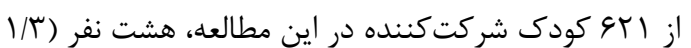

درصد) از نظر وجود آنتىبادى اختصاصى IgG ضد توكسوكارا
انسان از نظر بالينى به سه نوع قابل تفكيك است كه عبارت هستند

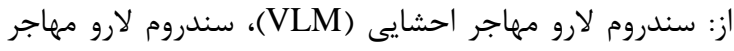

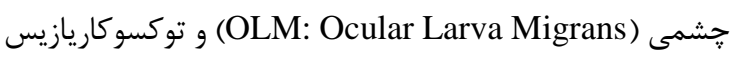

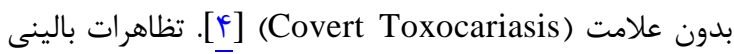
در اين عفونت به فاكتورهاى مختلفى از قبيل شدت آلودگى،

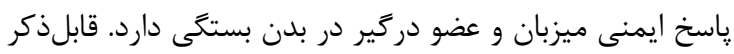

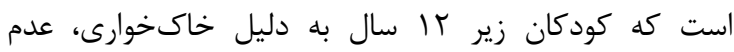

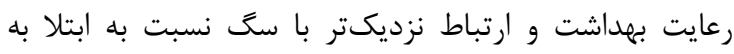

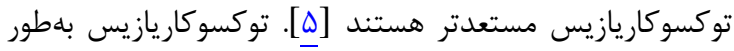

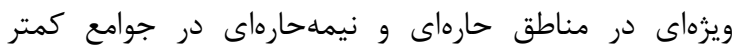

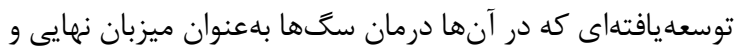

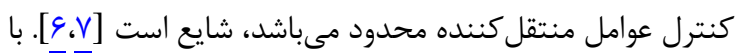

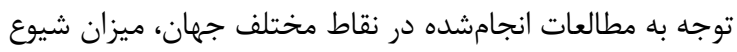

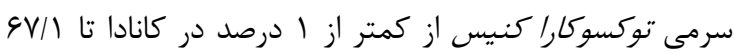

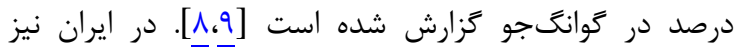

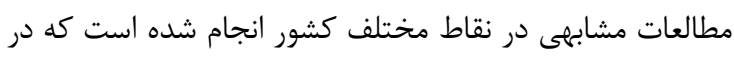

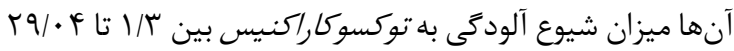

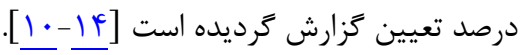
تنها روش قطعى براى تشخيص توكسوكاريازيس، مشاهده

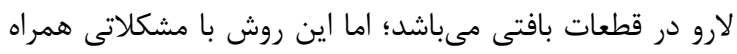

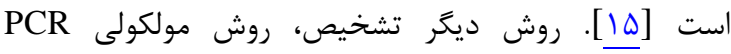
(Polymerase Chain Reaction) تصويربردارى نيز در تشخيص اين عفونت كمك كننده مىباشند

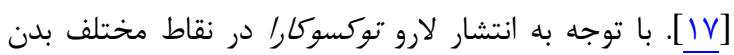

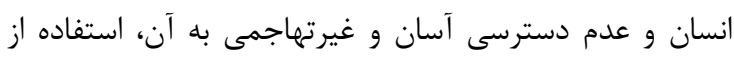

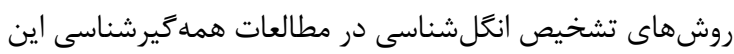

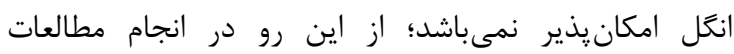

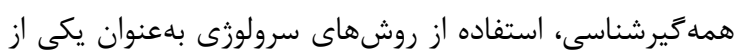

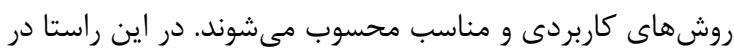

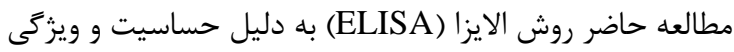
مناسب جهت تشخيص عفونت و مطالعات همه گيرشناسى مورد

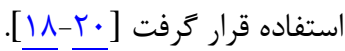

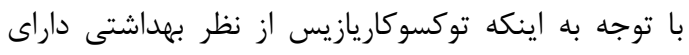

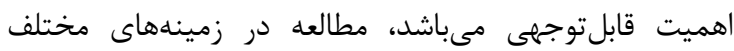

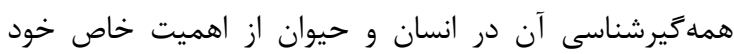

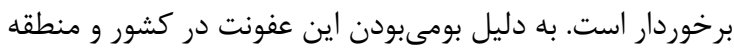

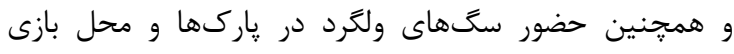

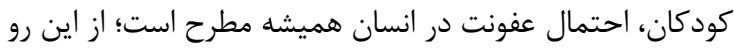

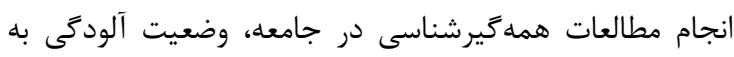

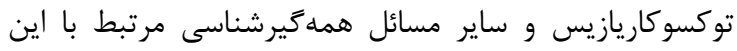

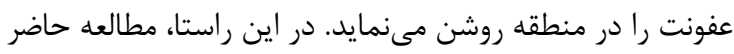

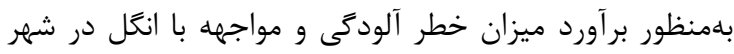

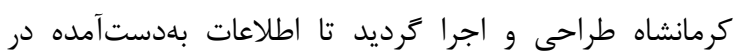

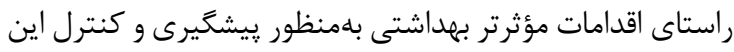


جدول ا: فراوانى وضعيت آنتىبادى ضد توكسوكاراكنيس در افراد شركت كننده در مطالعه بر حسب متغيرهاى جمعيتشناختى

\begin{tabular}{|c|c|c|c|c|c|}
\hline \multirow[t]{2}{*}{ معنادارى سطح } & مجموع & وضعيت سر مى & مثبت & & \multirow[t]{2}{*}{ متغير } \\
\hline & تعداد (درصد) & تعداد (درصد) & تعداد (درصد) & & \\
\hline \multirow{5}{*}{$\cdot / 0 \cdot t$} & $(1 \cdots) 11 \mathrm{~V}$ & $(9 \wedge / T) \backslash 10$ & $(1 / V) T$ & $r-r$ & \multirow{5}{*}{ سن } \\
\hline & $(1 \cdots) \mid \& \wedge$ & $(9 q / T) \backslash f V$ & $(\cdot / V) 1$ & $f-\theta$ & \\
\hline & $(1 \cdots) \mid r \cdot$ & $(9 \mathrm{~V} / \Delta) \backslash 1 \mathrm{~V}$ & $(T / \Delta) r$ & $4-V$ & \\
\hline & $(1 \cdots) 11$. & $(1 \cdots) 11$. & $\cdot$ & $1-9$ & \\
\hline & (1) (1) & $(q \Lambda / F) \mid Y F$ & $(1 / 9) T$ & $1 \cdot-14$ & \\
\hline \multirow{2}{*}{$\cdot / V T \Delta$} & Vוז & $(q \Lambda / F) r \mid r$ & $(1 / 9) \Delta$ & 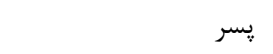 & \multirow{2}{*}{ جنس } \\
\hline & $(1 \cdot \cdot) r \cdot F$ & $(99) \Gamma \cdot 1$ & (1) r & دختر & \\
\hline \multirow{4}{*}{. MFD } & $(1 \cdot \cdot)^{r} \cdot q$ & $(99 / 4) r \cdot V$ & $(\cdot 18) T$ & بيسواد & \multirow{4}{*}{ تحصيلات والدين } \\
\hline & $(1 \cdots)$ rag & $(99 / \Gamma) Y \Delta)$ & $(1 / 9) \Delta$ & دييلم & \\
\hline & $(1 \cdots) \Delta 1$ & $(9 \wedge) \Delta \cdot$ & $(Y) 1$ & كارشناسى & \\
\hline & $(1 \cdots) \Delta$ & $(1 \cdots) \Delta$ & $(\cdot / \cdot) \cdot$ & كارشناسى ارشد و بالاتر & \\
\hline \multirow[t]{2}{*}{. } & $(1 \cdots) 019$ & $(9 / / 4) \Delta 11$ & $(1 / 8) \wedge$ & شهر & \multirow{2}{*}{ محل سكونت } \\
\hline & $(1 \cdot \cdot) 1 \cdot r$ & $(1 \cdot \cdot) 1 \cdot r$ & $(\cdot / \cdot) \cdot$ & 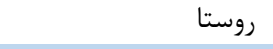 & \\
\hline \multirow[t]{2}{*}{1} & $(1 \cdots) \Delta q$ & $(1 \cdots) \Delta 9$ & $(\cdot / \cdot) \cdot$ & بله & \multirow{2}{*}{ سابقه خاكخوارى } \\
\hline & $(1 \cdots) \Delta S T$ & $(9 \wedge / q) \Delta \Delta F^{F}$ & $(1 / 4) \wedge$ & خير & \\
\hline \multirow[t]{2}{*}{1} & $(1 \cdots) F$ & $(1 \cdots) F$ & $(\cdot / \cdot) \cdot$ & بله & \multirow{2}{*}{ لمس و بازى با سگ } \\
\hline & $(1 \cdots) \Delta \wedge 1$ & $(9 \wedge / 9) \Delta V r$ & $(1 / 4) \wedge$ & خير & \\
\hline \multirow{2}{*}{1} & (1..) & $(99 / r) \mid r$. & $(\cdot \mid \Lambda) \mid$ & بله & \multirow{2}{*}{ بازى در محل تردد سگ } \\
\hline & $(1 \cdots)<q$. & $(9 \wedge / 9)$ FAץ & $\left(1 / F^{f}\right) V$ & خير & \\
\hline \multirow{2}{*}{.$/ D I T$} & (1) ( • & $(9 \wedge / 1) \Delta r$ & $(1 / 9) 1$ & بله & \multirow{2}{*}{ مصرف نيميز جكر يا كوشت مرغ خام } \\
\hline & $(1 \cdots) \Delta \& \Lambda$ & $(q \wedge / \wedge) \Delta 9)$ & $(1 / T) V$ & خير & \\
\hline
\end{tabular}

توكسوكارا كنيس مي توان به مطالعهاى كه در استان سيستان و

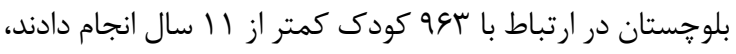

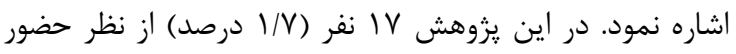

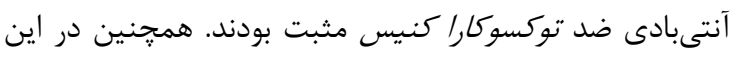

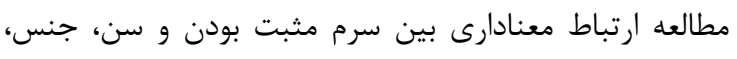

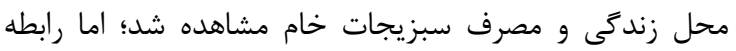

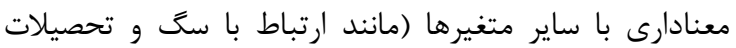

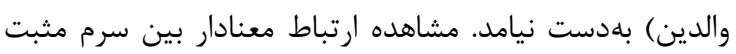

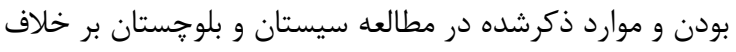

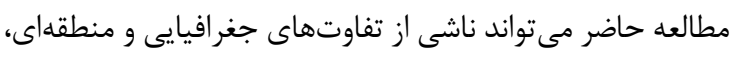

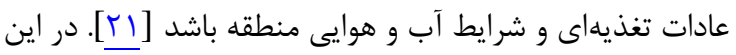

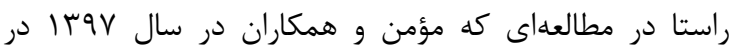

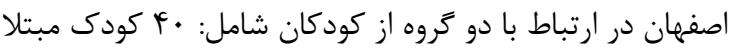

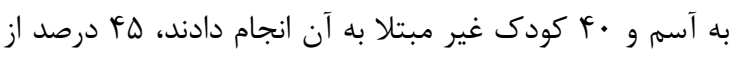

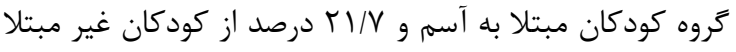

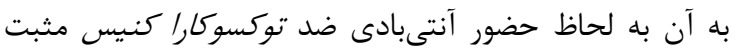

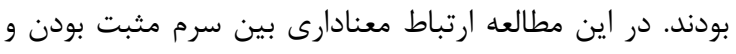

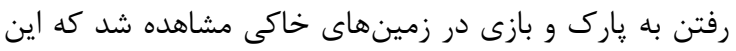

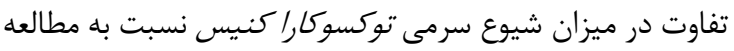

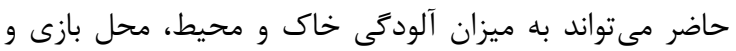

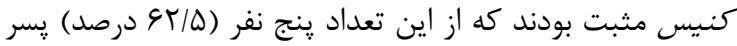

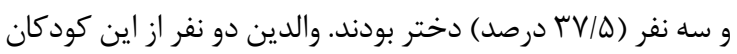

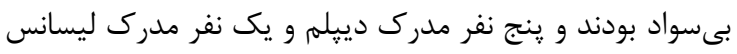

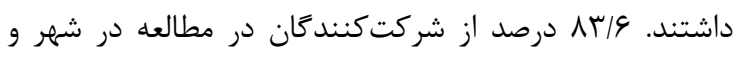

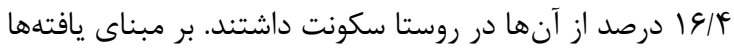

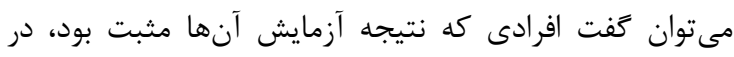

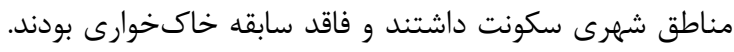

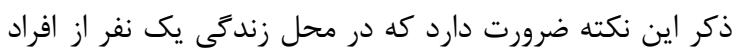

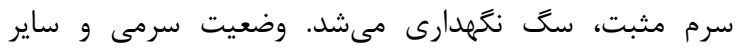

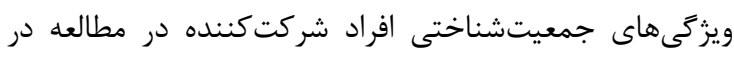

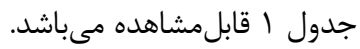

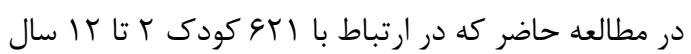
مراجعه كننده به شش مركز بهداشتى - درمانى در سطح شهر

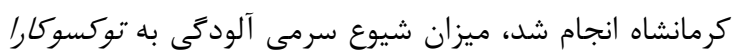

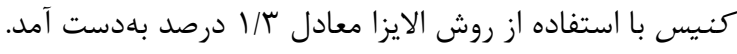

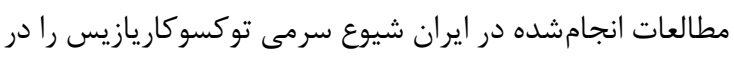

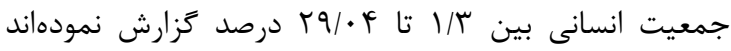

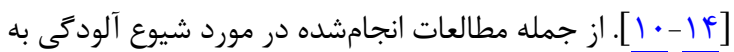


توكسوكارا كنيس كه در مطالعه ماهيدشت از نوع IgE بود، اشاره

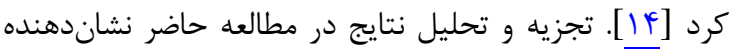

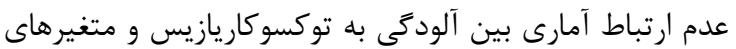

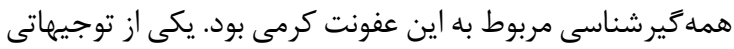

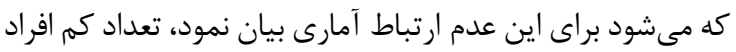

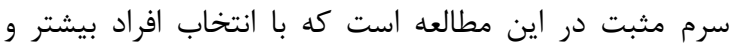

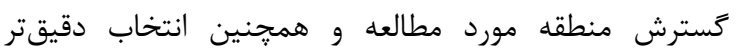

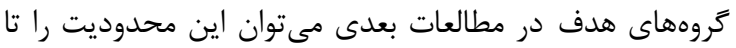

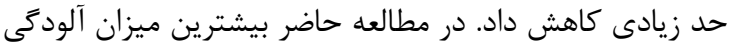

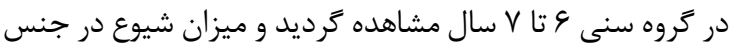

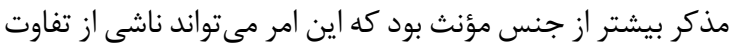

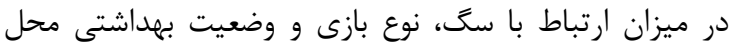

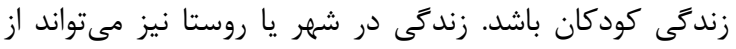

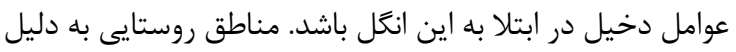

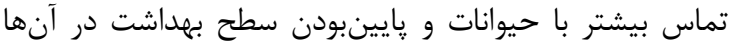

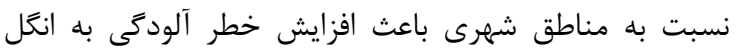

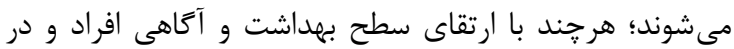

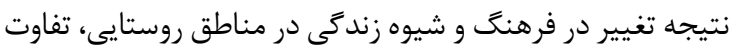

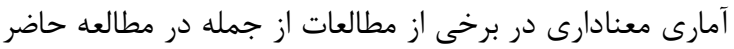

\section{نتيجه تيرى}

نتايج اين مطالعه نشان دادند كه ميزان شيوع آلودگى به توكسوكاريازيس در شهر كرمانشاه تا حدودى كمتر از ساير دئ داندي مناطق كشور مىباشد؛ اما با توجه به اهميت بهداشتى اين عفونت

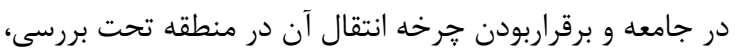

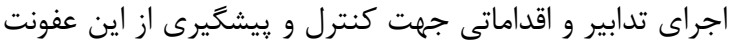
و همجنين افزايش سطح آثاهى عمومى افراد جامعه مى تواند

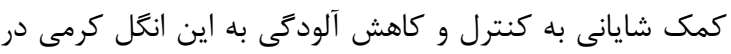
افراد و بهويزه در كودكان اين منطقه نمايد.

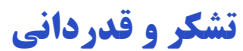

مقاله حاضر بركرفته از ياياننامه دوره كارشناسى ارشد رشته

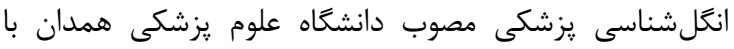

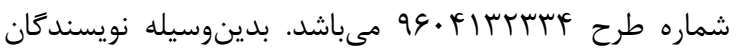
مراتب تشكر و قدردانى خود را از معاونت تحقيقات و فناورى

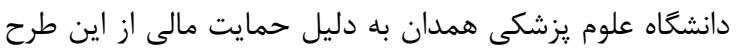

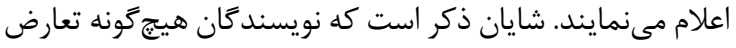
منافعى با نتايج ارائهشده ندارند.

\section{REFERENCES}

1. Pelloux H, Faure O. Toxocariasis in adults. Rev Med Interne. 2004;25(3):201-6. PMID: 15049281 DOI: $10.1016 / \mathrm{s} 0248-$ 8663(03)00258-3

2. Rubinsky-Elefant G, Hirata CE, Yamamoto JH, Ferreira MU.
همجٍنين تفاوت در جامعه مورد مطالعه وابسته باشد [Tr]. در

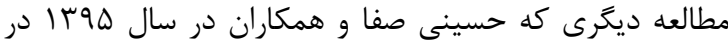

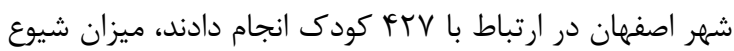

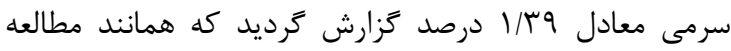

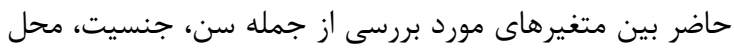

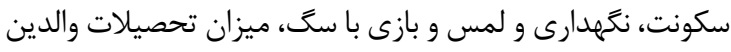

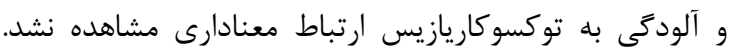
نتايج اين مطالعات كه در سالهاى اخير انجام شدهاند، با نتايج

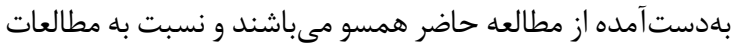
انجامشده در سالهاى كذشته، ميزان شيوع يايينترى را ران نشان

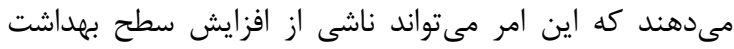

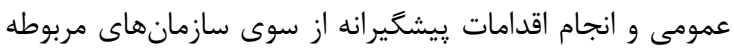

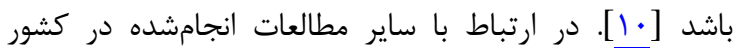

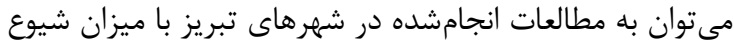

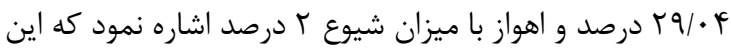

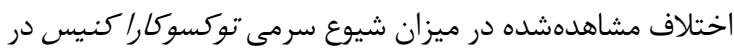

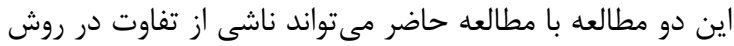

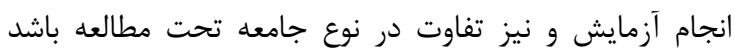
[11،11][1]. در غرب كشور نيز مطالعهاى توسط فلاح و همكاران

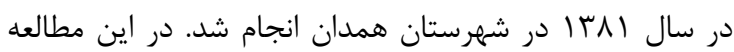

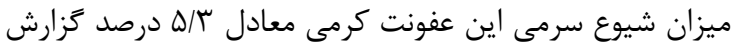

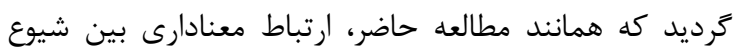

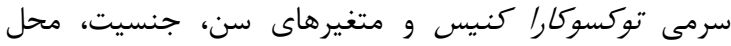

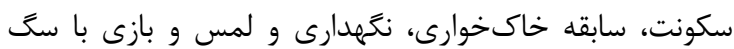

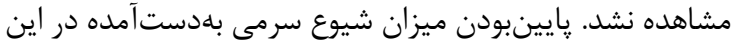

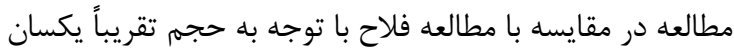

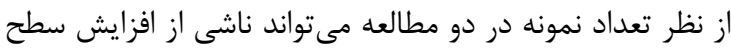

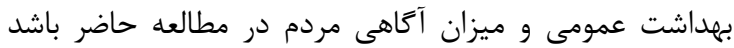

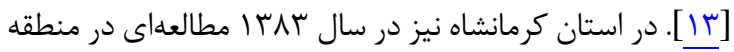

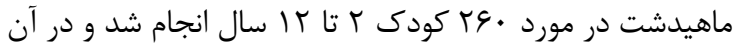

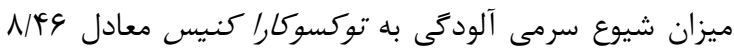

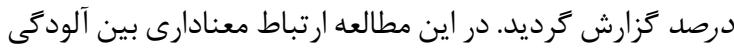
به توكسوكاريازيس و متغيرهاى جنسيت، سابقه خاك خوديد درارى و و

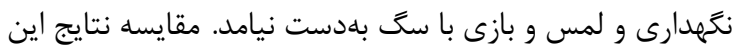

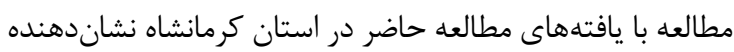

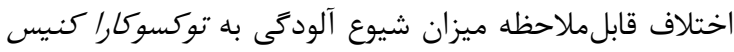

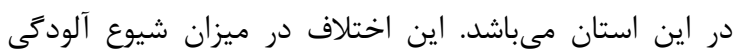

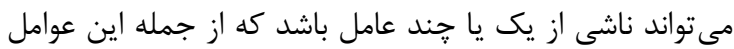
مى توان به اختلاف زمانى انجام مطالعات، اختلاف دان در منطق ئه مورد

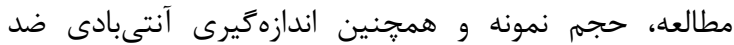

Human toxocariasis: diagnosis, worldwide seroprevalences and clinical expression of the systemic and ocular forms. Ann Trop Med Parasitol. 2010;104(1):3-23. PMID: 20149289 DOI: $10.1179 / 136485910 X 12607012373957$ 
3. Woodhall DM, Fiore AE. Toxocariasis: a review for pediatricians. J Pediatric Infect Dis Soc. 2014;3(2):154-9. PMID: 26625368 DOI: 10.1093/jpids/pit066

4. Muller R, Wakelin D. Worms and human disease. $2^{\text {nd }}$ ed. Wallingford: CABi, 2002.

5. Fan CK, Liao CW, Cheng YC. Factors affecting disease manifestation of toxocarosis in humans: genetics and environment. Vet Parasitol. 2013;193(4):342-52. PMID: 23290279 DOI: 10.1016/j.vetpar.2012.12.030

6. Hotez PJ, Wilkins PP: Toxocariasis: America's most common neglected infection of poverty and a helminthiasis of global importance? Plos Negl Trop Dis. 2009;3(3):e400. PMID: 19333373 DOI: 10.1371/journal.pntd.0000400

7. Hotez PJ, Dumonteil E, Heffernan MJ, Bottazzi ME. Innovation for the 'bottom 100 million': eliminating neglected tropical diseases in the Americas. Adv Exp Med Biol. 2013;764:1-12. PMID: 23654053 DOI: 10.1007/978-14614-4726-9_1

8. Lee Rm, Moore Lb, Bottazzi ME, Hotez PG. Toxocariasis in North America: a systematic review. PLoS Negl Trop Dis. 2014;8(8):e3116. PMID: 25166906 DOI: 10.1371/journal. pntd.0003116

9. Won EJ, Kim J, Shin MG, Shin JH, Suh SP, Ryang DW. Seroepidemiology of toxocariasis and its clinical implications in gwangju and Jeonnam-province, Korea. Ann Lab Med. 2015;35(4):449-53. PMID: 26131418 DOI: $10.3343 / \mathrm{alm}$. 2015.35.4.449

10. Hosseini-Safa A, Mousavi SM, Bahadoran Bagh Badorani M, Ghatreh Samani M, Mostafaei S, Yousofi Darani H. Seroepidemiology of toxocariasis in children (5-15 yr old) referred to the pediatric clinic of Imam Hossein hospital, Isfahan, Iran. Iran J Parasitol. 2015;10(4):632-7. PMID: 26811731

11. Fallah E, Mahami-Oskouei L, Mahami-Oskouei M, Safaiyan A. Evaluation of indirect immunofluorescent antibody (IFA) test and enzyme-linked immunosorbent assay (ELISA) in diagnosis of visceral larva migranas. J Ilam Univ Med Sci. 2013;21(7):87-93. [Persian]

12. Alavi SM, Sefidgaran GH. Frequency of anti toxocara antibodies in schoolchildren with chronic cough and eosinophilia in urban and rural area of Ahvaz, Iran in 2006.
Jundishapur Sci Med J. 2009;8(2):141-7.

13. Fallah M, Azimi A, Taherkhani H. Seroprevalence of toxocariasis in children aged 1-9 years in Hamadan - 2002. $J$ Zanjan Univ Med Sci Health Serv. 2005;13(50):44-50. [Persian]

14. Akhlaghi L, Ourmazdi H, Sarafnia A, Vaziri S, Jadidian $K$, Leghaii Z. An investigation on the toxocariasis seroprevalence in children (2-12 years old) from Mahidasht area of Kermanshah Province 2003-2004. Razi J Med Sci. 2006;13(52):41-8.

15. Nichols RL. The etiology of visceral larva migrans. I. Diagnostic morphology of infective second-stage Toxocara larvae. J Parasitol. 1956;42:349-62. PMID: 13346427

16. Jacobs DE, Zhu X, Gasser RB, Chilton NB. PCR-based methods for identification of potentially zoonotic ascaridoid parasites of the dog, fox and cat. Acta Trop. 1997;68(2):191200. PMID: 9386794

17. Romano N, Nor Azah MO, Rahmah N, Lim Y AL, Rohela M. Seroprevalence of toxocariasis among Orang Asli (Indigenous people) in Malaysia using two immunoassays. Trop Biomed. 2010;27(3):585-94. PMID: 21399601

18. de Savigny DH, Voller A, Woodruff AW. Toxocariasis: serological diagnosis by enzyme immunoassay. $J$ Clin Pathol. 1979;32(3):284-8. PMID: 372253 DOI: 10.1136/ jcp.32.3.284

19. Maizels RM, de Savigny D, Ogilvie BM. Characterization of surface and excretory-secretory antigens of Toxocara canis infective larvae. Parasite Immunol. 1984;6(1):23-37. PMID: 6701003 DOI: 10.1111/j.1365-3024.1984.tb00779.x

20. Engvall E, Perlmann P. Enzyme-linked immunosorbent assay (ELISA) Quantitative assay of immunoglobulin G. Immunochemistry. 1971;8(9):871-4. PMID: 5135623

21. Geraili A, Maarofi Y, Dabirzade M, Normohamadi H, Khoshsima shahraki M. A survey of gastrointestinal helminth of stray dogs in Zabol City, southeastern of Iran. Arch Razi Institute. 2016;71(1):57-60. DOI: 10.22034/ari.2016.105999

22. Momen T, Esmaeil N, Reisi M. Seroprevalence of toxocara canis in asthmatic children and its relation to the severity of diseases. Med Arch. 2018;72(3):174-7. PMID: 30061761 DOI: $10.5455 /$ medarh.2018.72.174-177 